\title{
Cortical Activity Predicts Which Older Adults Recognize Speech in Noise and When
}

\author{
ㅈenneth I. Vaden, Jr., ${ }^{1}$ Stefanie E. Kuchinsky, ${ }^{2}$ Jayne B. Ahlstrom, ${ }^{1}$ Judy R. Dubno, ${ }^{1}$ and Mark A. Eckert ${ }^{1}$ \\ ${ }^{1}$ Hearing Research Program, Department of Otolaryngology-Head and Neck Surgery, Medical University of South Carolina, Charleston, South Carolina \\ 29425, and ${ }^{2}$ Center for Advanced Study of Language, University of Maryland, College Park, Maryland 20742
}

\begin{abstract}
Speech recognition in noise can be challenging for older adults and elicits elevated activity throughout a cingulo-opercular network that is hypothesized to monitor and modify behaviors to optimize performance. A word recognition in noise experiment was used to test the hypothesis that cingulo-opercular engagement provides performance benefit for older adults. Healthy older adults $(N=31 ; 50-81$ years of age; mean pure tone thresholds $<32 \mathrm{~dB}$ HL from 0.25 to $8 \mathrm{kHz}$, best ear; species: human) performed word recognition in multitalker babble at 2 signal-to-noise ratios ( $\mathrm{SNR}=+3$ or $+10 \mathrm{~dB}$ ) during a sparse sampling fMRI experiment. Elevated cingulo-opercular activity was associated with an increased likelihood of correct recognition on the following trial independently of SNR and performance on the preceding trial. The cingulo-opercular effect increased for participants with the best overall performance. These effects were lower for older adults compared with a younger, normal-hearing adult sample $(N=18)$. Visual cortex activity also predicted trial-level recognition for the older adults, which resulted from discrete decreases in activity before errors and occurred for the oldest adults with the poorest recognition. Participants demonstrating larger visual cortex effects also had reduced fractional anisotropy in an anterior portion of the left inferior frontal-occipital fasciculus, which projects between frontal and occipital regions where activity predicted word recognition. Together, the results indicate that older adults experience performance benefit from elevated cingulo-opercular activity, but not to the same extent as younger adults, and that declines in attentional control can limit word recognition.
\end{abstract}

Key words: aging; attention; audition; control; perception; speech

\section{Introduction}

Speech recognition in noise requires considerable effort and focused attention, which can elicit activity in a cingulo-opercular network that includes the dorsal paracingulate, anterior insula, and frontal opercula (Eckert et al., 2009; Wild et al., 2012; Vaden et al., 2013). Cingulo-opercular activity is frequently observed with uncertainty and errors for a range of tasks (Duncan and Owen, 2000; Braver et al., 2001; Dosenbach et al., 2006) and is thought to facilitate adaptive control (i.e., adjusting behavior and monitoring outcomes to optimize performance). Indeed, cingulo-opercular activity has been observed to predict subsequent behavior for younger adults (Carter et al., 2000; Kerns et

\footnotetext{
Received July 16, 2014; revised Jan. 14, 2015; accepted Jan. $28,2015$.
}

Author contributions: K.I.V., J.B.A., J.R.D., and M.A.E. designed research; K.I.V., S.E.K., and M.A.E. performed research; K.I.V. contributed unpublished reagents/analytic tools; K.I.V., S.E.K., and M.A.E. analyzed data; K.I.V., S.E.K., J.B.A., J.R.D., and M.A.E. wrote the paper.

This work was supported (in part) by the National Institute on Deafness and 0ther Communication Disorders, National Institutes of Health (Grant P50 DC 000422); the Medical University of South Carolina Center for Biomedical Imaging; the South Carolina Clinical and Translational Research Institute; and the National Center for Research Resources, National Institutes of Health (Grant UL1 RR029882). This investigation was conducted in a facility constructed with support from the Research Facilities Improvement Program, National Center for Research Resources, National Institutes of Health (Grant C06 RR14516). We thank Bob Dougherty for thoughtful comments and the participants for their involvement in this study.

The authors declare no competing financial interests.

Correspondence should be addressed to either Mark A. Eckert or Kenneth I. Vaden Jr, Hearing Research Program, Department of Otolaryngology-Head and Neck Surgery, Medical University of South Carolina, 135 Rutledge Avenue, MSC 550, Charleston, SC 29425-5500. E-mail: eckert@musc.edu or vaden@musc.edu.

DOI:10.1523/JNEUROSCI.2908-14.2015

Copyright $\odot 2015$ the authors $\quad 0270-6474 / 15 / 353929-09 \$ 15.00 / 0$ al., 2004; Weissman et al., 2006; Eichele et al., 2008; Vaden et al., 2013). Although age-related increases in cingulo-opercular activity are observed during speech recognition in noise (Sharp et al., 2006; Harris et al., 2009; Erb and Obleser, 2013), this may reflect increased difficulty for older adults (Dubno et al., 1984; Humes and Christopherson, 1991; Souza et al., 2007), which raises questions about whether frontal activity supports speech recognition with increasing age.

Older adults demonstrate elevated prefrontal cortex activation in response to increased difficulty across a range of tasks compared with younger adults (Schneider-Garces et al., 2010; Stern et al., 2012; Ennis et al., 2013), which is hypothesized to reflect a compensatory response to enhance performance (Reuter-Lorenz and Cappell, 2008; Davis et al., 2008). This premise is indirectly supported by observations that older adults with better performance often exhibit greater cingulo-opercular activity than poorer performers (Reuter-Lorenz et al., 2000; Cabeza et al., 2002; Reuter-Lorenz and Lustig, 2005; but see Meinzer et al., 2012). In the present study, we tested this prediction in the context of adaptive control by investigating whether cinguloopercular activity predicted trial-level performance for older adults.

During perceptual tasks, elevated prefrontal activity can occur with elevated activity in sensory and association cortices, which appears to reflect the enhancement of relevant sensory representations (Davis et al., 2008; Grady, 2012; Erb and Obleser, 2013). Older adults also have exhibited increased visual cortex activity 
while performing speech recognition and other listening tasks (Fernandes et al., 2006; Eckert et al., 2008; Peiffer et al., 2009; Kuchinsky et al., 2012). This activity may support word recognition because early visual cortex activity encodes category information for sounds (Vetter et al., 2014) and is sensitive to the imageability of spoken words (Lewis and Poeppel, 2014).

Alternatively, cross-modal activity during a unimodal task could reflect impaired performance (Sandmann et al., 2012). For example, declines in frontally mediated suppression of irrelevant visual processing would be predicted to relate to poorer performance (Gazzaley and D'Esposito, 2007; Campbell et al., 2012). The inferior frontal fasciculus (IFOF) provides an avenue for communication between frontal and visual cortices where white matter microstructure has been related to cognitive function (Peters et al., 2014) and declines with age (Teipel et al., 2010; Yeatman et al., 2014). We also tested the prediction that the IFOF supports the control of visual processes by characterizing the relationship between microstructure and visual activity during word recognition.

\section{Materials and Methods}

Participants. Thirty-one healthy middle-aged to older adult participants (19 female; $50-81$ years of age; $60.2 \pm 8.1$, mean $\pm \mathrm{SD}$ ) were selected for the present study on the basis of demonstrating generally normal hearing. The selected participants were native English speakers with a mean Edinburgh handedness questionnaire score of $76.1 \pm 46.1$ from a possible range of -100 (strongly left-handed) to 100 (strongly right-handed; Oldfield, 1971). The participants had an average of $15.5 \pm 2.3$ years of education and exhibited little or no mild cognitive impairment based on their Mini Mental Status Examination (Folstein, Robins, and Helzer, $1983)$ performance $(29.0 \pm 0.8$ of 30 items; cf. Tombaugh and McIntyre, 1992). The participants reported no history of neurological or psychiatric events. Informed consent was obtained in compliance with the Institutional Review Board at the Medical University of South Carolina and experiments were conducted in accordance with the Declaration of Helsinki.

Audiometric assessment. Pure tone thresholds were measured with a Madsen OB922 audiometer and TDH-39 headphones that were calibrated to American National Standards Institute standards (American National Standards Institute, 2010). On average, the participants had normal hearing up to $4 \mathrm{kHz}$ with gradually sloping hearing loss at higher frequencies. Each participant had mean pure tone thresholds $<32 \mathrm{~dB} \mathrm{HL}$ from 0.25 to $8 \mathrm{kHz}$ (best ear), no more than $10 \mathrm{~dB}$ differences between mean pure-tone thresholds for the right and left ears, and normal immittance measures.

Stimuli. Speech intelligibility was experimentally manipulated by varying the signal-to-noise ratios (SNR) of words presented in a multitalker babble. Digital recordings of 120 monosyllabic consonant-vowelconsonant words spoken by a male (Dirks et al., 2001) were presented to both ears with Sensimetrics piezoelectric insert ear phones. A recording of continuous multitalker babble from the Speech Perception in Noise test (Kalikow et al., 1977) was presented at $82 \mathrm{~dB}$ SPL and words were presented at either $85 \mathrm{~dB}$ SPL ( $+3 \mathrm{~dB}$ SNR) or $92 \mathrm{~dB} \mathrm{SPL} \mathrm{(+} 10 \mathrm{~dB}$ SNR). The presentation levels were calibrated in the scanner control room before the experiment. The multitalker babble recording consisted of 12 talkers, which results in energetic speech masking similar to steady-state noise presented at the same SNR (Miller, 1947; Carhart et al., 1969; Wilson et al., 2012). Each word was presented in one SNR condition to avoid potential interactions between intelligibility and item recognition or priming.

Experimental procedure. The word recognition experiment and scanning protocol (sparse acquisition with $\mathrm{TR}=8.6 \mathrm{~s}$ ) used in the present study were also used with younger adults in Vaden et al. (2013). Each session consisted of two word recognition epochs (60 TRs each), two babble-only epochs (15 TRs each), and three rest intervals (10 TRs each) at the beginning, middle, and end of the experiment. Each word recognition epoch consisted of 60 trials, during which participants performed a word recognition task in multitalker babble $(+3$ or $+10 \mathrm{~dB}$ SNR).
Words were presented in one SNR condition for four to six consecutive trials to limit the predictability of transitions between blocks of SNR condition trials. Participants were instructed to listen to each word presented and repeat the word aloud or, if the word was not recognized, to say "nope." Performance feedback was not provided during the experiment. An onscreen cue prepared participants for each word recognition epoch with the words "get ready," which was viewed on a projection screen through a periscope mirror mounted on the head coil. During each word recognition trial, a crosshair appeared onscreen and changed color from white to red to indicate the beginning and back to white to indicate the ending of the response interval (Fig. 1).

Word recognition scores. Two raters listened to participant responses during the experiment and scored responses as correct whenever the participant repeated the word exactly as it was presented. Word recognition scores from the two raters agreed for $93.23 \%$ of the trials and discrepancies were clarified using recordings collected with an MRI-compatible microphone (Magnetic Resonance Technologies). Unintelligible or missing responses were omitted from analyses (135 trials across subjects) and "nope" responses were scored as incorrect ( 87 trials across subjects).

Structural and functional image acquisition. A Siemens $3 \mathrm{~T}$ scanner and 32-channel head coil were used to collect structural and functional images. The T1-weighted images were acquired in 160 slices with a $256 \times$ 256 matrix $, \mathrm{TR}=8.13 \mathrm{~ms}, \mathrm{TE}=3.7 \mathrm{~ms}$, flip angle $=8^{\circ}$, slice thickness $=$ $1.0 \mathrm{~mm}$, and no slice gap. A single-shot echoplanar imaging sequence was used to acquire 180 whole-brain functional images (36 slices with $64 \times$ 64 matrix, $\mathrm{TR}=8.6 \mathrm{~s}, \mathrm{TE}=35 \mathrm{~ms}$, acquisition time: $\mathrm{TA}=1647 \mathrm{~ms}$, slice thickness $=3.0 \mathrm{~mm}$, gap $=0$, sequential order, GRAPPA-parallel imaging with acceleration factor $=2$ ). Each functional image had $3.0 \mathrm{~mm}$ isomorphic voxels.

Preprocessing. The anatomical T1-weighted images were iteratively normalized using the Advanced Normalization Tools (ANTS version 1.9; Avants et al., 2011) to create a study-specific space for functional analyses (Avants and Gee, 2004; Vaden et al., 2012). Each participant's preprocessed functional image data were coregistered to their native space anatomical image and then spatially warped to match the study-specific template using the ANTS-derived parameters. The Montreal Neurological Institute (MNI) coordinates for peak effects were also determined with ANTS by spatially transforming the study-specific template to the MNI template and then applying those parameters to peak voxel coordinates in the study-specific space.

Each participant's functional blood oxygen level-dependent (BOLD) data were preprocessed using SPM8 software (www.fil.ion.ucl.ac. $\mathrm{uk} / \mathrm{spm}$ ) to realign, unwarp, and coregister each functional image to the corresponding structural scan before spatial normalization and smoothing with a Gaussian kernel (FWHM $=8 \mathrm{~mm}$ ). No participants or trials were excluded due to head motion. Across participants, the largest triallevel translations were $\leq 1.86 \mathrm{~mm}$ and rotations $\leq 0.04^{\circ}$ based on Pythagorean distance estimates from the motion parameters (http://www.nitrc. org/projects/pythagoras). The Linear Model of the Global Signal method (Macey et al., 2004) was used to residualize the global mean signal from the preprocessed images. Next, two signal outlier vectors were produced that represented images with extreme values using an algorithm detailed in Vaden et al. (2010), which identified $4.48 \%$ of the functional images with voxel or volume intensities that exceeded $2.5 \mathrm{SDs}$ from the mean time series intensity. In addition to the two signal outlier vectors, four nuisance vectors summarized changes in head position and motion (Kuchinsky et al., 2012; Wilke, 2012). For the general linear mixed model (GLMM) analyses described below, the data were high-pass filtered (1/ $128 \mathrm{~Hz}$ ) and nuisance regressors were residualized from the BOLD data using multiple regression.

General linear model analysis: BOLD contrast. A general linear model (GLM) analysis was performed in SPM8 to test the predictions that BOLD contrast was elevated in cingulo-opercular regions during a word recognition in noise task with two SNR conditions (i.e., +3 dB SNR > $+10 \mathrm{~dB}$ SNR) and when participants made recognition errors (i.e., incorrect $>$ correct). Salient transitions between experiment blocks were also included in the model to disambiguate these effects on BOLD contrast from performance related activity by specifying the initial trial of rest, babble, or word recognition blocks as transition events. The GLM 


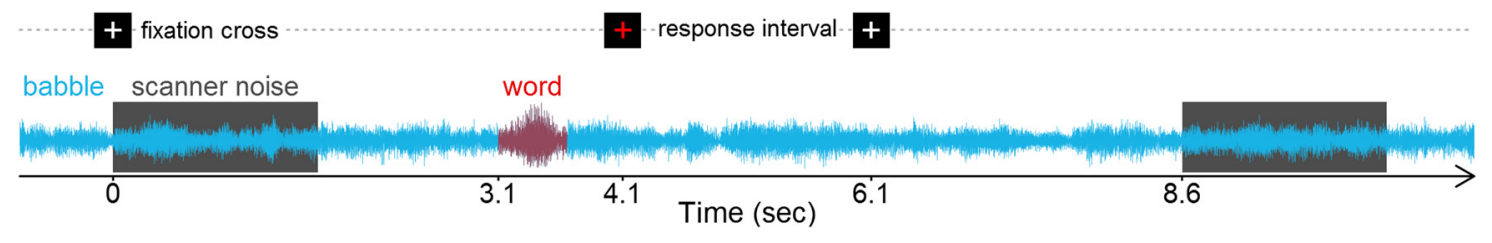

Figure 1. Experimental design. Each word recognition trial in the fMRI experiment included a fixed presentation and response timing that was synchronized to the onset of the sparse-sampling acquisition (TR $=8.6 \mathrm{~s}$ ). This timing allowed precise SNR manipulations for each aural word presentation in continuous multitalker babble and allowed participant responses to be recorded without gradient noise. Visually cued response intervals also provided participants enough time to stabilize their head after each response to limit head motion during the image acquisition.

specified each trial as discrete events: $(1)+3 \mathrm{~dB}$ SNR word recognition, (2) + $10 \mathrm{~dB}$ SNR word recognition, (3) babble presentations, or (4) transitions and included parameters for correct or incorrect recognition. Subject-level effect maps were submitted to group-level statistic tests to identify consistent changes in BOLD contrast across participants.

GLMM analysis: word recognition. A GLMM-based logistic regression analysis was performed to test the prediction that increased BOLD contrast in cingulo-opercular regions was associated with correct recognition of the next word that was presented ( $\mathrm{R}$ statistics software version 2.15.0 with R-packages: lme4, version 0.999375.42, AnalyzeFMRI, version 1.1-14). Binary word recognition $(W)$ for each trial $(t)$ was specified as the dependent variable and trials were excluded that immediately followed a different SNR condition or rest (i.e., first trial of each block). The GLMM that was used for voxel-level analyses included the following predictors: (1) SNR condition, (2) BOLD contrast measured before the word presentation $\left(B O L D_{\mathrm{t}-1}\right),(3) S N R \times B O L D$ interaction, and (4) random subject effects $(1 \mid S U B)$, which can be expressed: $W_{\mathrm{t}}=S N R_{\mathrm{t}}+$ $B O L D_{\mathrm{t}-1}+S N R_{\mathrm{t}} \times B O L D_{\mathrm{t}-1}+(1 \mid S U B)+$ error. For the trials that were included in the GLMM analysis (2797 trials), each participant's data were centered and scaled within SNR condition to ensure that signal variability did not reflect participant or SNR-dependent intensity differences (Vaden et al., 2013). Standard estimates for the BOLD effect on subsequent recognition, referred to as betas in the present study, were calculated by modifying the random effects term $\left(1+B O L D_{t-1} \mid S U B\right)$ and then pooling results for each participant within each significant cluster to examine potential associations with participant age and mean word recognition.

Follow-up logistic regression analyses were performed using the GLMM detailed above with binarized voxel time series to characterize whether discrete increases or decreases in BOLD contrast accounted for subsequent word recognition. Thresholds were used on the SNR-scaled BOLD to define discrete increases $(\theta>1 \mathrm{SD})$ and discrete decreases $(\theta<$ $-1 \mathrm{SD}$ ) in each voxel time series. Control analyses were also performed for trials that followed a correct response (1556 trials) or trials that only followed an incorrect response (1241 trials) to determine the extent to which the effects could be driven by post-error improvements in performance (Rabbitt, 1966; Laming, 1979).

Statistic map thresholds. Each statistic map was submitted to a voxel statistic threshold of $Z>2.33, p_{\mathrm{UNC}}=0.01$ and FWE-corrected cluster extent threshold of $p_{\mathrm{FWE}}<0.05$ (Friston et al., 1994; Worsley, 2006; FMRISTAT) for the GLM and GLMM analyses. Although this is a relatively conservative threshold (Hayasaka and Nichols, 2003), especially given the previous findings involving cingulo-opercular activity (Vaden et al., 2013), this was used to appropriately threshold effects that occurred outside of the predicted cingulo-opercular regions.

Replication and age differences. Age-related differences in cinguloopercular effects on trial-level word recognition were examined by comparing betas obtained from the present sample of older adults and those from younger adults ( $N=18$; aged $20-38$ years), previously reported in Vaden et al. (2013). First, we identified significant results that were consistent in the younger and older groups by estimating the conjoint significance for independent tests (Uncapher and Rugg, 2005) based on group statistic maps from each study in the template space of the present study. Results from the previous study were spatially transformed using ANTS (Avants et al., 2011) and then group-level $t$-statistic maps from each study were masked inclusively with a $p_{\text {unc }}<0.01$ voxel threshold and multiplied so that the replication map had a conjoint- $p_{\mathrm{UNC}}<0.0001$.
Subject-level betas were estimated using GLMMs and pooled across cingulo-opercular voxels that were significantly predictive of performance in the younger and older adult groups. These betas were then compared between age groups to characterize differences in the recognition benefit from cingulo-opercular engagement.

Diffusion tensor imaging. Tract-based fractional anisotropy (FA) analyses were performed to examine the extent to which age-related functional imaging effects could be explained by variation in white matter microstructure. We tested the prediction that age-related differences in visual cortex activity during an aural word recognition task stem from age-related structural differences in the left IFOF (Martino et al., 2010), which connects frontal and occipital regions where activity related to correct recognition on the next trial.

Diffusion imaging acquisition parameters include: 32-channel head coil, GRAPPA with acceleration factor $=2$, B-values $=0,1000$, 64 directions, $\mathrm{TE}=88 \mathrm{~ms}, \mathrm{TR}=8000 \mathrm{~ms}$, flip angle $=90^{\circ}, \mathrm{FOV}=208 \mathrm{~mm}$, image dimensions $=104 \times 104 \times 64$ slices, and $2 \mathrm{~mm}^{3}$ isomorphic voxels. Eddy current correction and tensor fitting was performed using the FMRIB Diffusion Toolbox (Behrens et al., 2003). The diffusion images from each participant were coregistered to their native space T1 image using the SPM mutual information algorithm and then imported into MR Diffusion (http://vistalab.stanford.edu/software) so that deterministic streamlines tractography could be performed across all voxels (Yeatman et al., 2012).

Whole brain tractography was performed using Automated Fiber Quantification and mrDiffusion (AFQ; Yeatman et al., 2012) with default settings to only include tracts with angle $<30^{\circ}$, FA $>0.2$, and tract lengths between 50 and $250 \mathrm{~mm}$. IFOF fibers were defined by streamline fibers intersecting frontal and occipital regions of interest (ROIs) that were spatially transformed from MNI space into native space using AFQ calls to SPM8. The anterior ROI was a plane in coronal orientation spanning the extent of frontal white matter that was placed at the anterior border of the corpus callosum genu. The posterior ROI was a plane in coronal orientation extending medial to lateral from the anterior boundary of the cuneus to the preoccipital notch and superiorly to the parietooccipital sulcus. One participant was excluded from statistical analyses because only 29 fibers were identified in the IFOF, which was too few to obtain reliable FA estimates along this tract.

Multiple-comparison-corrected correlation tests were performed on core-weighted FA values that were calculated for 100 evenly spaced positions (i.e., "nodes") between the frontal and occipital ROIs along the center of each participant's IFOF in native space using AFQ. This approach normalizes the distances along each native-space tract so that Pearson correlations can be performed across subjects (Yeatman et al., 2011; Wandell and Yeatman, 2013). Because statistic results in neighboring tract positions are spatially non-independent, results were corrected for multiple comparisons using nonparametric permutation tests (corrected two-tailed $\alpha=0.05$; Nichols and Holmes, 2002). The FA values were averaged across the significantly predictive nodes for control analyses. Additional control analyses were performed to determine whether cortical atrophy affected the diffusion imaging results by averaging the distance from each significant node to the nearest gray matter voxel (50\% or greater gray matter probability, SPM8 New Segment Tool). Tensor linearity, planarity, and sphericity (Westin et al., 2002) were used to characterize the influence of tensor shape on FA effects. 


\section{Results}

Task-related activity and word recognition

Cingulo-opercular cortex exhibited increased BOLD contrast when participants made word recognition errors and to a lesser extent for the difficult $+3 \mathrm{~dB}$ SNR condition compared with the $+10 \mathrm{~dB}$ SNR condition (Fig. 2, Table 1). The conjunction analysis results demonstrated that a similar pattern of results was observed for the younger adults in Vaden et al. (2013), although older adults were more likely to exhibit left superior temporal sulcus activity and exhibited dorsal cingulate/paracingulate activity that was less sensitive to differences in SNR compared to the younger group.

In the older adult sample, word recognition was poorer in the $+3 \mathrm{~dB}$ SNR $(42.6 \pm 6.8 \%)$ compared with the $+10 \mathrm{~dB}$ SNR condition $(70.4 \pm 7.3 \%)$, a significant difference in the GLMM: $Z=-13.61, p<0.001$. Mean word recognition across SNR conditions was not related to age $(r=$ $-0.23, p=0.21)$ or average pure tone threshold $(r=-0.30, p=$ 0.10 for best ear threshold: 0.25 to $8 \mathrm{kHz}$ ). Therefore, the task produced cingulo-opercular activity and variable performance amenable to trial-level analyses.

\section{BOLD contrast and subsequent word recognition}

Correct word recognition was significantly more likely after trials with elevated activity in cingulo-opercular regions that included the left inferior frontal gyrus, right anterior insula and frontal operculum, and dorsal cingulate or paracingulate. Control analyses showed that elevated BOLD contrast was associated with word recognition for trials that followed correct responses or incorrect responses (Table 2, top). The same pattern of results was observed for younger adults, with the exception of posterior cuneus and occipitotemporal regions in visual cortex that were predictive of trial-level performance for older adults (Fig. 3A, Table 2, top).

Word recognition benefit from elevated cingulo-opercular activity was relatively limited for older adults compared with younger adults, with significantly lower cingulo-opercular effects (i.e., pooled betas) for older compared with younger adults $(Z=$ $-5.24, p<0.001$; Fig. $3 B$ ). Among the older adults, however, age was not related to the betas $(r=-0.11, p=0.56)$. These results indicate that age effects on adaptive control began before the age of this middle-aged to older adult sample (i.e., earlier than age 50).

The visual cortex effects were not observed in the younger adult sample and increased with age for older adult group $(r=$ $0.37, p=0.04)$. The visual cortex effects were predicted to stem from transient changes in directed attention, reflected by a decrease in visual cortex activity before word recognition errors. Indeed, a discrete reduction in posterior cuneus activity was significantly associated with incorrect recognition on the next trial (97 voxels or $83.6 \%$ of the cluster in Fig. $3 A$ ).

\section{Individual differences in word recognition and activity}

Older adults with evidence of greater trial-level benefit from preceding cingulo-opercular activity demonstrated better overall word recognition $(r=0.49, p=0.005$; Fig. $3 C)$. This effect was present after controlling for age (partial $r=0.48, p=0.006$ ). In contrast, the occipital betas pooled from visual cortex revealed a

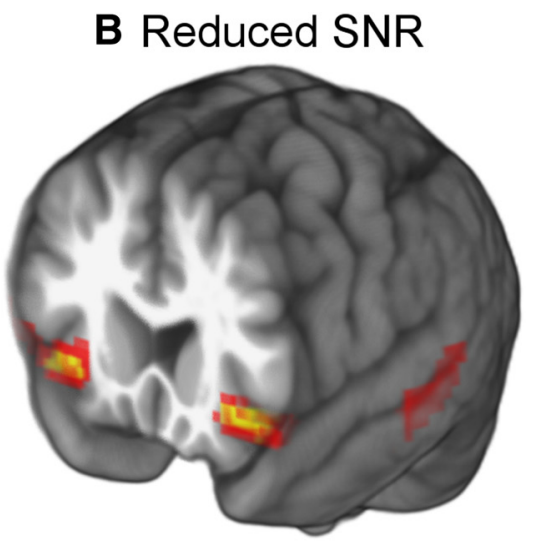

B Reduced SNR

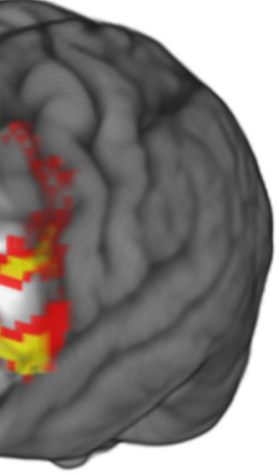

Responses

Figure 2. Elevated activity was observed in cingulo-opercular cortex during incorrect word recognition trials $(\boldsymbol{A})$ and in the anterior insula, inferior frontal gyrus, and orbitofrontal cortex, bilaterally $(\boldsymbol{B})$ for trials with reduced speech intelligibility (red: $p_{\text {UNC }}$ Table 1. GLM results: changes in BOLD activity

\begin{tabular}{|c|c|c|c|}
\hline Description of cluster extent & Peak Z & \# Voxels & Peak MNI \\
\hline \multicolumn{4}{|l|}{ Incorrect $>$ correct } \\
\hline Anterior to middle cingulate, dorsal paracingulate & 4.57 & $591^{* * *}$ & $2,15,50$ \\
\hline $\begin{array}{l}\text { L. anterior insula, L. inferior frontal gyrus and } \\
\text { sulcus, L. precentral sulcus }\end{array}$ & 4.04 & $587^{* * *}$ & $-38,24,-4$ \\
\hline R. anterior insula, R. inferior frontal gyrus & 4.55 & $458^{* * *}$ & $40,21,-2$ \\
\hline $\begin{array}{l}\text { R. parietal-occipital sulcus and isthmus, } \\
\text { calcarine sulcus }\end{array}$ & 3.81 & $203 * * *$ & $10,-79,12$ \\
\hline R. middle frontal gyrus, R. inferior frontal sulcus & 3.48 & $131^{* *}$ & $49,26,34$ \\
\hline \multicolumn{4}{|l|}{ Correct $>$ incorrect } \\
\hline \multicolumn{4}{|l|}{$+3 \mathrm{~dB}$ SNR $>+10 \mathrm{~dB}$ SNR } \\
\hline $\begin{array}{l}\text { R. anterior insula, R. inferior frontal gyrus, R. } \\
\text { orbitofrontal cortex }\end{array}$ & 3.53 & $297^{* * *}$ & $59,30,4$ \\
\hline $\begin{array}{l}\text { L. anterior insula, L. inferior frontal gyrus (pars } \\
\text { orbitalis), L. orbitofrontal cortex }\end{array}$ & 4.54 & $219^{* *}$ & $-44,15,-8$ \\
\hline $\begin{array}{l}\text { L. posterior to mid superior temporal sulcus, L. } \\
\text { middle temporal gyrus }\end{array}$ & 3.26 & $95^{*}$ & $-64,-21,-15$ \\
\hline $\begin{array}{l}\text { R. mid superior temporal sulcus, R. middle } \\
\text { temporal gyrus }\end{array}$ & 3.58 & $84^{*}$ & $55,-30,-8$ \\
\hline \multicolumn{4}{|l|}{$+10 \mathrm{~dB}$ SNR $>+3 \mathrm{~dB}$ SNR } \\
\hline $\begin{array}{l}\text { Posterior cingulate, precuneus, parietal-occipi- } \\
\text { tal sulcus, R. parietal operculum, R. post- } \\
\text { central gyrus }\end{array}$ & 4.18 & $2007^{* * *}$ & $-9,0,33$ \\
\hline R. inferior parietal lobule & 4.28 & $236^{* * *}$ & $42,-78,36$ \\
\hline L. inferior parietal lobule & 4.00 & $138^{* *}$ & $-49,-73,30$ \\
\hline
\end{tabular}

Asterisks denote familywise error-corrected significance for each cluster: ${ }^{*} p_{\mathrm{FWE}}<0.05$, ${ }^{* *} p_{\mathrm{FWE}}<0.01,{ }^{* * *} p_{\mathrm{FWE}}<0.001$ $L$, left; R, right (otherwise bilateral).

\section{Table 2. BOLD signals correlated with performance on the next trial}

\begin{tabular}{lclc}
\hline Description & Peak $Z$ & $\#$ Voxels & Peak MNI \\
\hline Main effects of BOLD activity & & & \\
$\quad$ L. inferior frontal gyrus and sulcus & 3.82 & $232_{\mathrm{AB}}$ & $-55,13,32$ \\
$\quad$ L. occipito-temporal cortex, L. posterior superior & 3.09 & $213_{\mathrm{AB}}$ & $-50,-75,16$ \\
$\quad$ temporal sulcus & & & \\
$\quad$ Cingulate sulcus, paracingulate & 3.92 & $164_{\mathrm{AB}}$ & $-3,21,40$ \\
$\quad$ R. anterior insula, R. inferior frontal gyrus & 3.35 & $151_{\mathrm{A}}$ & $50,23,2$ \\
$\quad$ Posterior medial cuneus & 3.47 & $116_{\mathrm{A}}$ & $6,-93,22$ \\
SNR $\times$ BOLD interaction & & & \\
$\quad$ R. superior temporal gyrus, R. Heschl's gyrus & 3.63 & $179_{\mathrm{AB}}$ & $56,-29,13$ \\
$\quad$ Anterior medial cuneus & 3.05 & $139_{\mathrm{B}}$ & $0,-73,15$ \\
$\quad$ (-) R. middle to posterior cingulate/paracingulate & -3.65 & $389_{\mathrm{AB}}$ & $6,-1,54$ \\
\hline
\end{tabular}

Subscripts $A$ and $B$ denote that significant voxels were found in each cluster when control analyses were restricted to post-correct trials or post-error trials, respectively.

$\mathrm{L}$, left; $\mathrm{R}$, right (otherwise bilateral). 

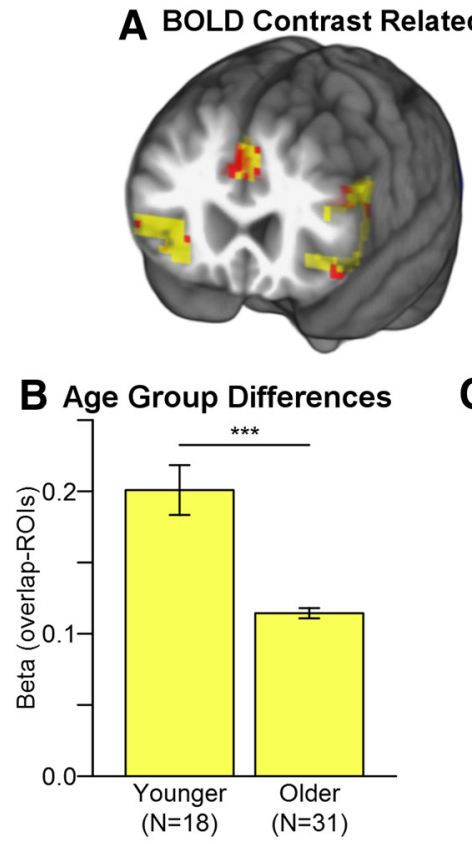
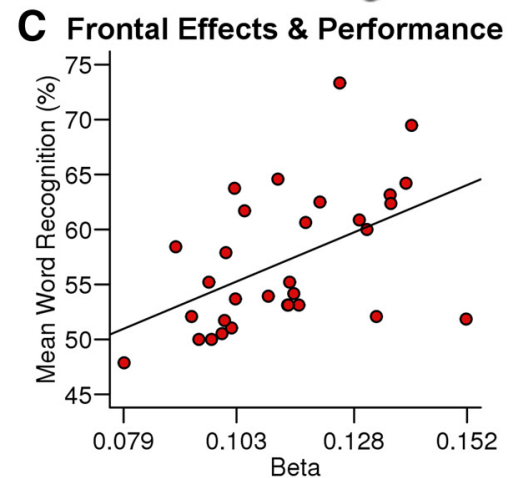

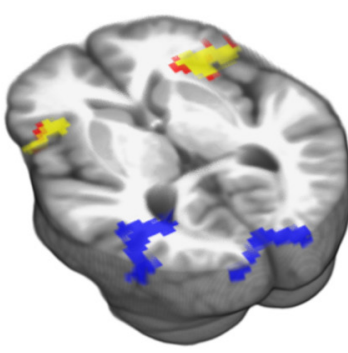

D Occipital Effects \& Performance

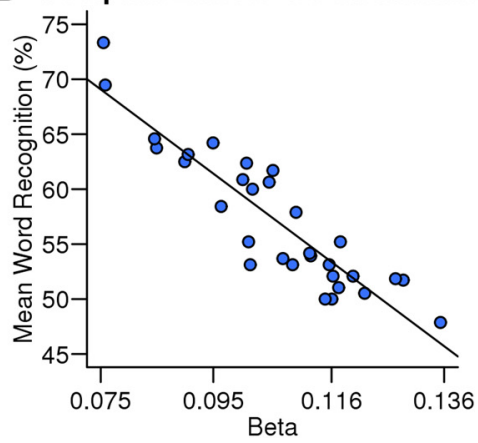

Figure 3. $A$, Elevated activity in cingulo-opercular cortex was related to an increased likelihood of word recognition on the next trial (red: $p_{\mathrm{UNC}}=0.01$; yellow: cingulo-opercular effects that overlapped with Vaden et al., 2013, with conjunction $p_{\text {UNC }}<0.0001$ ). $\boldsymbol{B}$, Individual effects (betas) from the replicated cingulo-opercular regions were significantly lower for the present sample of older adults than for the younger adults (Vaden et al., 2013). C, D, Individual effects from the cingulo-opercular clusters and occipital clusters exhibited positive and negative relationships, respectively, with mean word recognition for the older adults.
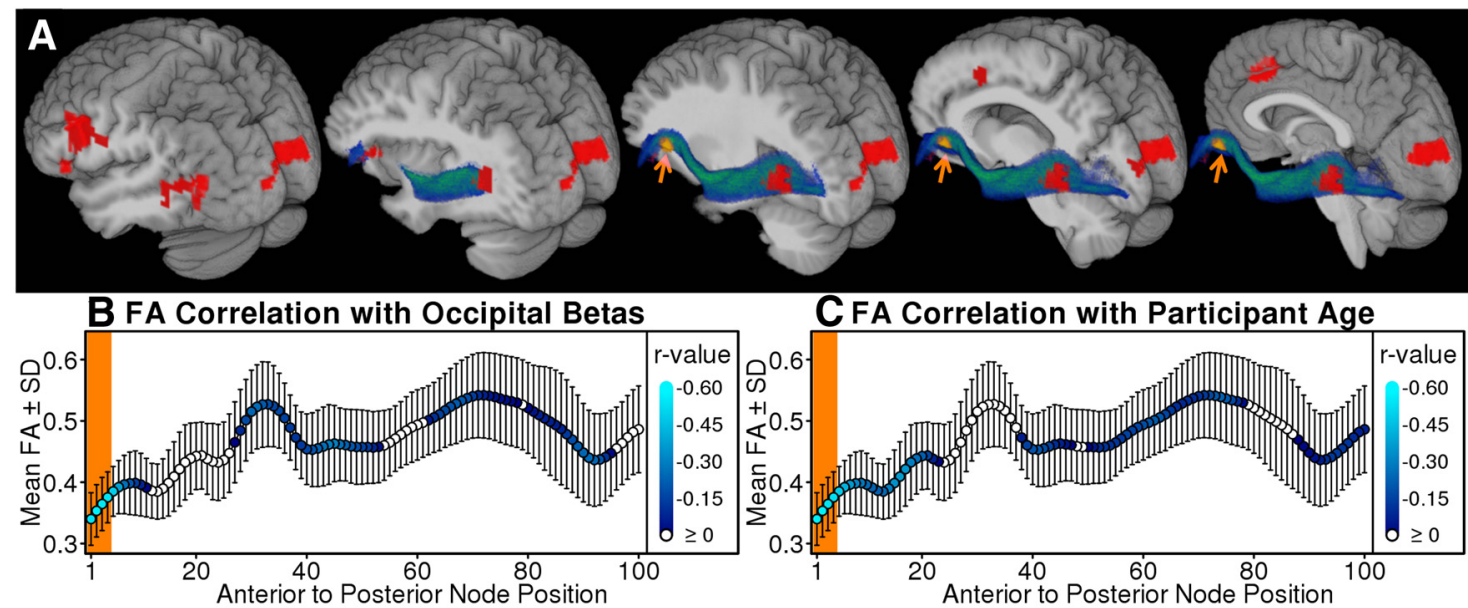

Figure 4. FA was lower in the left anterior IFOF for the participants with higher occipital betas and for the older participants. $\boldsymbol{A}$, The left IFOF rendered as a spatially normalized and averaged blue-green tract with the structural image peeled away in sagittal slices toward the midline. Red indicates voxels with BOLD related to subsequent word recognition. The IFOF projects between the frontal operculum and the occipital cortex, close to the clusters identified using the GLMM. B, C, Average FA and SDs are plotted for each position and filled lighter blue points that indicate stronger negative correlations between $F A$ and occipital betas $(\boldsymbol{B})$ or participant age $(\boldsymbol{C}$. The orange background $(\boldsymbol{B}, \boldsymbol{C})$ indicates significant negative correlations that were corrected for multiple comparisons using nonparametric permutation tests (corrected $\alpha=0.05$; Nichols and Holmes, 2002). The nodes with FA that were significantly related to occipital betas $(\boldsymbol{A}$; positions $1-4)$ were spatially transformed from native space and rendered onto the study template as the orange spot with arrows $(\boldsymbol{A})$. Pooled FA scores (positions $1-4)$ were related to occipital betas after controlling for mean distance to gray matter (partial $r=-0.42, p=0.02$ ) and participant age (partial $r=-0.58, p<0.001$ ), indicating that cortical atrophy and volume averaging did not account for the $\mathrm{FA} \mathrm{results.}$ This interpretation is also supported by tensor shape data (Westin et al., 2002). Tensor planarity can also reflect volume averaging and did not account for the associations between pooled FA and occipital betas (partial $r=-0.62, p<0.001$ ) or age (partial $r=-0.62, p<0.001$ ). In contrast, tensor linearity could explain the occipital beta associations with FA (partial $r=-0.19, p=0.31$ ), indicating that participants with stronger visual cortex effects and lower FA scores also had diffusion tensors with less uniform orientation in the left anterior IFOF.

different pattern (Fig. 3D). Participants with larger visual cortex effects had poorer mean word recognition $(r=-0.91, p<0.001$; Fig. 3D). This result remained significant after controlling for age and hearing threshold (partial $r<-0.90, p<0.001$ ).

Posterior activations and tract-based fractional anisotropy The left inferior frontal and occipital regions identified above in the trial-level analyses are connected by the IFOF (Fig. 4A). Lower
FA values were observed across the left IFOF in the older participants who exhibited a strong relation between visual cortex activity and word recognition. The occipital betas were significantly associated with FA values in the four most anterior positions in the IFOF after multiple-comparison correction $\left(r \leq-0.56, p_{\mathrm{COR}}\right.$ $\leq 0.04$; Fig. $4 B$ ) and FA values in those anterior positions also decreased with increasing participant age $\left(r \leq-0.55, p_{\mathrm{COR}} \leq\right.$ 0.04; Fig. 4C). Importantly, the relationship between participant 
age and occipital betas $(r=0.37, p=0.04)$ was not significant after controlling for FA scores pooled across positions 1-4 (partial $r=0.04, p=0.85 ; R^{2}$ decrease $=-0.14$ ), indicating that FA differences in the anterior IFOF accounted for the age-related differences in occipital betas. The FA values in the right IFOF were not related to visual cortex effects ( $p_{\mathrm{COR}}>0.39$ ), suggesting that the visual cortex effects were more likely to occur with agerelated declines in the left IFOF.

\section{Discussion}

The present results address a long-standing hypothesis for cognitive and perceptual aging by examining brain activity in relation to subsequent performance on a trial-by-trial basis. Middle-aged to older adults were more likely to recognize words in noise after elevated cingulo-opercular activity, an effect that was the most pronounced for participants with better overall word recognition. Although the cingulo-opercular results from the present sample of older adults spatially overlapped with effects previously obtained with younger adults (Vaden et al., 2013), age-group differences in word recognition benefit from cingulo-opercular activity indicate that this normal response to challenging task conditions declines with age. The impact of aging on word recognition was also demonstrated by visual cortex associations with trial-level word recognition that occurred when there was a drop in activity and subsequent performance. The visual cortex results were unique to the older adult sample, increased with advancing age, and related to evidence of microstructure declines within IFOF fibers. Together, the results highlight the importance of adaptive control and the direction of attention for successful word recognition in older adults.

Cingulo-opercular cortex is sensitive to task outcomes (Dosenbach et al., 2007; Eckert et al., 2009) and the cingulate in particular is thought to reflect intention to engage in a task based on potential outcomes (Shenhav et al., 2013). Activity across these regions increases when behaviorally relevant information is presented and can increase tonic alertness (Sadaghiani et al., 2010,2012 ) to enhance performance monitoring and adapt behavior (Carter et al., 2000; Kerns et al., 2004; Weissman et al., 2006; Eichele et al., 2008). Increasing activity in this adaptive control system would therefore be expected to optimize subsequent task performance.

The cingulo-opercular cortex has been characterized as a domain general network based on its function for a range of perceptual and cognitive tasks (Dosenbach et al., 2006), as well as functional connectivity without specific task demands (Dosenbach et al., 2007). We interpret the relatively large number of cingulo-opercular results from speech production and perception studies with challenging listening conditions (Adank, 2012) as evidence that language tasks can elicit domain general adaptive control functions. Elevated cingulo-opercular BOLD responses also have been observed in aphasia patients with better language task performance, raising important questions about the contribution of adaptive control and language networks (Geranmayeh et al., 2014a).

Importantly, our word recognition in noise task involved speech production to assess recognition, which means that cingulo-opercular activity could reflect the engagement of hypothesized speech control mechanisms (Tourville and Guenther, 2011; Hickok, 2012). Speech control models are broadly consistent with the hypothesized adaptive control function for the cingulo-opercular network, but more specifically propose that frontal cortex facilitates the detection and repair of speech errors. Indeed, cingulo-opercular activity robustly increased during errors without external feedback in the present experiment and in Vaden et al. (2013). Adaptive control during language tasks may recruit domain general and language-specific systems to support communication (Geranmayeh et al., 2014b; Simmonds et al., 2014), including response selection (Rodd et al., 2005; Davis et al., 2011) or inhibition of alternative responses (Xue et al., 2008).

The present cingulo-opercular results are important because they show when performance is likely to be optimal on a trial-bytrial basis. This is a methodological, but also a conceptual difference from previous studies in which elevated frontal activity across blocks of trials was observed for older adults with the best performance (Reuter-Lorenz et al., 2000; Cabeza et al., 2002; Cabeza, 2002; Reuter-Lorenz and Cappell, 2008; Wierenga et al., 2008). We observed that better performing participants exhibited a greater ability to drive the cingulo-opercular adaptive control system to support performance, at least for a basic and familiar word recognition in noise task. This result supports the proposal from cognitive aging models that frontal activity is compensatory (Reuter-Lorenz and Cappell, 2008; Davis et al., 2008).

Word recognition benefit from cingulo-opercular activity in the older adults was significantly lower compared with a younger adult group, even when comparing beta values from cinguloopercular regions that were significant predictors of word recognition in both samples. Higher pure-tone thresholds for the older than younger participants was considered as a possible explanation for the group difference in word recognition benefit. However, given that audibility of the speech was determined by the background noise and not listeners' pure-tone thresholds, hearing differences among subjects are unlikely to be the source of reduced benefit for older than younger adults. Rather, age-related declines occurring in the central auditory system (Harris et al., 2009; Peelle et al., 2011; Eckert et al., 2012; Erb and Obleser, 2013) and/or declines in the prefrontal cortex (Raz et al., 1997; Good et al., 2001; Resnick et al., 2003; Salat et al., 2004; Eckert, 2011) are more likely to account for the cingulo-opercular age group differences. Although there may have been developmental differences between age groups, these group differences are predicted to stem from central declines that occur during middle age because we did not observe a linear association between the betas and age within the broad age distribution of the middle-aged to older adult sample.

Age-related differences within the older adult group were observed for visual cortex activity. Elevated visual cortex activity during aural tasks is commonly observed in studies of older adults (Peelle et al., 2010; Kuchinsky et al., 2012). Our trial-level results support the premise that control of visual attention can be critical for word recognition. In particular, discrete decreases in posterior cuneus activity occurred before word recognition errors. This finding is consistent with evidence that older adults are susceptible to distraction during aural tasks (Tun et al., 2002; Guerreiro et al., 2010; Guerreiro and Van Gerven, 2011).

Age-related executive function declines have been associated with changes in frontal and occipital white matter (Grieve et al., 2007; Kennedy and Raz, 2009; Peters et al., 2014). Although we limited our fiber tract analyses to the IFOF because of its spatial correspondence to the functional results, our findings suggest that structural declines limit selective attention and word recognition in noise as a result. Specifically, lower FA values were seen in the left anterior IFOF for the oldest adults with stronger visual cortex effects. This association was primarily driven by reduced linearity of diffusion tensors, which can be affected by the density of axon membranes (Alexander et al., 2000; Beaulieu, 2002; Mori and Zhang, 2006). Therefore, age-related declines in the ability to 
maintain attention (Lustig et al., 2001; Tun et al., 2009) during speech recognition in noise are predicted to stem, at least in part, from IFOF declines.

In summary, our results indicate that elevated cinguloopercular activity occurs before word recognition. This result is important because it suggests, together with evidence for performance benefit from conflict adaptation (Kan et al., 2013), that methods to engage cingulo-opercular activity may enhance communication. The visual cortex results suggest that methods for maintaining attention or redirecting attention to a task also have the potential to enhance performance (Weissman et al., 2006), particularly for older adults. Together, the cingulo-opercular results and the visual cortex results indicate when older adults are more likely to understand words in noise and which older adults are more likely to have word recognition difficulties.

\section{References}

Adank P (2012) The neural bases of difficult speech comprehension and speech production: two activation likelihood estimation (ALE) metaanalyses. Brain Lang 122:42-54. CrossRef Medline

Alexander AL, Hasan K, Kindlmann G, Parker DL, Tsuruda JS (2000) A geometric analysis of diffusion tensor measurements of the human brain. Magn Reson Med 44:283-291. CrossRef Medline

American National Standards Institute (2010) American national standards specification for audiometers. New York: American National Standards Institute.

Avants B, Gee JC (2004) Geodesic estimation for large deformation anatomical shape averaging and interpolation. Neuroimage 23:S139-S150. CrossRef Medline

Avants BB, Tustison NJ, Song G (2011) Advanced normalization tools. Available from: www.picsl.upenn.edu/ANTS. Accessed June 22, 2010.

Beaulieu C (2002) The basis of anisotropic water diffusion in the nervous system-a technical review. NMR Biomed 15:435-455. CrossRef Medline

Behrens TE, Woolrich MW, Jenkinson M, Johansen-Berg H, Nunes RG, Clare S, Matthews PM, Brady JM, Smith SM (2003) Characterization and propagation of uncertainty in diffusion-weighted MR imaging. Magn Reson Med 50:1077-1088. CrossRef Medline

Braver TS, Barch DM, Gray JR, Molfese DL, Snyder A (2001) Anterior cingulate cortex and response conflict: effects of frequency, inhibition and errors. Cereb Cortex 11:825-836. CrossRef Medline

Cabeza R (2002) Hemispheric asymmetry reduction in older adults: the HAROLD model. Psychol Aging 17:85-100. CrossRef Medline

Cabeza R, Anderson ND, Locantore JK, McIntosh AR (2002) Aging gracefully: compensatory brain activity in high-performing older adults. Neuroimage 17:1394-1402. CrossRef Medline

Campbell KL, Grady CL, Ng C, Hasher L (2012) Age differences in the frontoparietal cognitive control network: implications for distractibility. Neuropsychologia 50:2212-2223. CrossRef Medline

Carhart R, Tillman TW, Greetis ES (1969) Perceptual masking in multiple sound backgrounds. J Acoust Soc Am 45:694-703. CrossRef Medline

Carter CS, Macdonald AM, Botvinick M, Ross LL, Stenger VA, Noll D, Cohen JD (2000) Parsing executive processes: strategic vs. evaluative functions of the anterior cingulate cortex. Proc Natl Acad Sci U S A 97:1944-1948. CrossRef Medline

Davis MH, Ford MA, Kherif F, Johnsrude IS (2011) Does semantic context benefit speech understanding through "top-down" processes? Evidence from time-resolved sparse fMRI. J Cogn Neurosci 23:3914-3932. CrossRef Medline

Davis SW, Dennis NA, Daselaar SM, Fleck MS, Cabeza R (2008) Qué PASA? The posterior-anterior shift in aging. Cereb Cortex 18:1201-1209. Medline

Dirks DD, Takayanagi S, Moshfegh A, Noffsinger PD, Fausti SA (2001) Examination of the neighborhood activation theory in normal and hearingimpaired listeners. Ear Hear 22:1-13. Medline

Dosenbach NU, Visscher KM, Palmer ED, Miezin FM, Wenger KK, Kang HC, Burgund ED, Grimes AL, Schlaggar BL, Petersen SE (2006) A core system for the implementation of task sets. Neuron 50:799-812. CrossRef Medline

Dosenbach NU, Fair DA, Miezin FM, Cohen AL, Wenger KK, Dosenbach RA, Fox MD, Snyder AZ, Vincent JL, Raichle ME, Schlaggar BL, Petersen SE
(2007) Distinct brain networks for adaptive and stable task control in humans. Proc Natl Acad Sci U S A 104:11073-11078. CrossRef Medline

Dubno JR, Dirks DD, Morgan DE (1984) Effects of age and mild hearing loss on speech recognition in noise. J Acoust Soc Am 76:87-96. CrossRef Medline

Duncan J, Owen AM (2000) Common regions of the human frontal lobe recruited by diverse cognitive demands. Trends Neurosci 23:475-483. CrossRef Medline

Eckert MA (2011) Slowing down: age-related neurobiological predictors of processing speed. Front Neurosci 5:25. CrossRef Medline

Eckert MA, Walczak A, Ahlstrom J, Denslow S, Horwitz A, Dubno JR (2008) Age-related effects on word recognition: reliance on cognitive control systems with structural declines in speech-responsive cortex. J Assoc Res Otolaryngol 9:252-259. CrossRef Medline

Eckert MA, Menon V, Walczak A, Ahlstrom J, Denslow S, Horwitz A, Dubno JR (2009) At the heart of the ventral attention system: the right anterior insula. Hum Brain Mapp 30:2530-2541. CrossRef Medline

Eckert MA, Cute SL, Vaden KI Jr, Kuchinsky SE, Dubno JR (2012) Auditory cortex signs of age-related hearing loss. J Assoc Res Otolaryngol 13:703713. CrossRef Medline

Eichele T, Debener S, Calhoun VD, Specht K, Engel AK, Hugdahl K, von Cramon DY, Ullsperger M (2008) Prediction of human errors by maladaptive changes in event-related brain networks. Proc Natl Acad Sci U S A 105:6173-6178. CrossRef Medline

Ennis GE, Hess TM, Smith BT (2013) The impact of age and motivation on cognitive effort: implications for cognitive engagement in older adulthood. Psychol Aging 28:495-504. CrossRef Medline

Erb J, Obleser J (2013) Upregulation of cognitive control networks in older adults' speech comprehension. Front Syst Neurosci 7:116. CrossRef Medline

Fernandes MA, Pacurar A, Moscovitch M, Grady C (2006) Neural correlates of auditory recognition under full and divided attention in younger and older adults. Neuropsychologia 44:2452-2464. CrossRef Medline

Folstein MF, Robins LN, Helzer JE (1983) The Mini-Mental State Examination. Arch Gen Psychiatry 40:812. CrossRef Medline

Friston KJ, Worsley KJ, Frackowiak RS, Mazziotta JC, Evans AC (1994) Assessing the significance of focal activations using their spatial extent. Hum Brain Mapp 1:210-220. CrossRef Medline

Gazzaley A, D’Esposito M (2007) Top-down modulation and normal aging. Ann NY Acad Sci 1097:67-83. CrossRef Medline

Geranmayeh F, Brownsett SL, Wise RJ (2014a) Task-induced brain activity in aphasic stroke patients: what is driving recovery? Brain 137:2632-2648. CrossRef Medline

Geranmayeh F, Wise RJ, Mehta A, Leech R (2014b) Overlapping networks engaged during spoken language production and its cognitive control. J Neurosci 34:8728-8740. CrossRef Medline

Good CD, Johnsrude IS, Ashburner J, Henson RN, Friston KJ, Frackowiak RS (2001) A voxel-based morphometric study of ageing in 465 normal adult human brains. Neuroimage 14:21-36. CrossRef Medline

Grady C (2012) The cognitive neuroscience of ageing. Nat Rev Neurosci 13:491-505. CrossRef Medline

Grieve SM, Williams LM, Paul RH, Clark CR, Gordon E (2007) Cognitive aging, executive function, and fractional anisotropy: a diffusion tensor MR imaging study. Am J Neuroradiol 28:226-235. Medline

Guerreiro MJ, Van Gerven PW (2011) Now you see it, now you don't: evidence for age-dependent and age-independent cross-modal distraction. Psychol Aging 26:415-426. CrossRef Medline

Guerreiro MJ, Murphy DR, Van Gerven PW (2010) The role of sensory modality in age-related distraction: a critical review and a renewed view. Psychol Bull 136:975-1022. CrossRef Medline

Harris KC, Dubno JR, Keren NI, Ahlstrom JB, Eckert MA (2009) Speech recognition in younger and older adults: a dependency on low-level auditory cortex. J Neurosci 29:6078-6087. CrossRef Medline

Hayasaka S, Nichols TE (2003) Validating cluster size inference: random field and permutation methods. Neuroimage 20:2343-2356. CrossRef Medline

Hickok G (2012) Computational neuroanatomy of speech production. Nat Rev Neurosci 13:135-145. CrossRef Medline

Humes LE, Christopherson L (1991) Speech identification difficulties of hearing-impaired elderly persons: the contributions of auditory processing deficits. J Speech Hear Res 34:686-693. CrossRef Medline

Kalikow DN, Stevens KN, Elliott LL (1977) Development of a test of speech 
intelligibility in noise using sentence materials with controlled word predictability. J Acoust Soc Am 61:1337-1351. CrossRef Medline

Kan IP, Teubner-Rhodes S, Drummey AB, Nutile L, Krupa L, Novick JM (2013) To adapt or not to adapt: the question of domain-general cognitive control. Cognition 129:637-651. CrossRef Medline

Kennedy KM, Raz N (2009) Aging white matter and cognition: differential effects of regional variations in diffusion properties on memory, executive functions, and speed. Neuropsychologia 47:916-927. CrossRef Medline

Kerns JG, Cohen JD, MacDonald AW 3rd, Cho RY, Stenger VA, Carter CS (2004) Anterior cingulate conflict monitoring and adjustments in control. Science 303:1023-1026. CrossRef Medline

Kuchinsky SE, Vaden KI Jr, Keren NI, Harris KC, Ahlstrom JB, Dubno JR, Eckert MA (2012) Word intelligibility and age predict visual cortex activity during word listening. Cereb Cortex 22:1360-1371. CrossRef Medline

Laming D (1979) Choice reaction performance following an error. Acta Psychol 43:199-224. CrossRef

Lewis G, Poeppel D (2014) The role of visual representations during the lexical access of spoken words. Brain Lang 134:1-10. CrossRef Medline

Lustig C, Hasher L, Tonev ST (2001) Inhibitory control over the present and the past. Eur J Cogn Psychol 13:107-122.

Macey PM, Macey KE, Kumar R, Harper RM (2004) A method for removal of global effects from fMRI time series. Neuroimage 22:360-366. CrossRef Medline

Martino J, Brogna C, Robles SG, Vergani F, Duffau H (2010) Anatomic dissection of the inferior fronto-occipital fasciculus revisited in the lights of brain stimulation data. Cortex 46:691-699. CrossRef Medline

Meinzer M, Flaisch T, Seeds L, Harnish S, Antonenko D, Witte V, Lindenberg R, Crosson B (2012) Same modulation but different starting points: performance modulates age differences in inferior frontal cortex activity during word-retrieval. PLoS One 7:e33631. CrossRef Medline

Miller GA (1947) The masking of speech. Psychol Bull 44:105-129. CrossRef Medline

Mori S, Zhang J (2006) Principles of diffusion tensor imaging and its applications to basic neuroscience research. Neuron 51:527-539. CrossRef Medline

Nichols TE, Holmes AP (2002) Nonparametric permutation tests for functional neuroimaging: a primer with examples. Hum Brain Mapp 15:1-25. Medline

Oldfield RC (1971) The assessment and analysis of handedness: the Edinburgh inventory. Neuropsychologia 9:97-113. CrossRef Medline

Peelle JE, Troiani V, Wingfield A, Grossman M (2010) Neural processing during older adults' comprehension of spoken sentences: age differences in resource allocation and connectivity. Cereb Cortex 20:773-782. CrossRef Medline

Peelle JE, Troiani V, Grossman M, Wingfield A (2011) Hearing loss in older adults affects neural systems supporting speech comprehension. J Neurosci 31:12638-12643. CrossRef Medline

Peiffer AM, Hugenschmidt CE, Maldjian JA, Casanova R, Srikanth R, Hayasaka S, Burdette JH, Kraft RA, Laurienti PJ (2009) Aging and the interaction of sensory cortical function and structure. Hum Brain Mapp 30: 228-240. CrossRef Medline

Peters BD, Ikuta T, DeRosse P, John M, Burdick KE, Gruner P, Prendergast DM, Szeszko PR, Malhotra AK (2014) Age-related differences in white matter tract microstructure are associated with cognitive performance from childhood to adulthood. Biol Psychiatry 75:248-256. CrossRef Medline

Rabbitt PM (1966) Errors and error correction in choice-response tasks. J Exp Psychol 71:264-272. CrossRef Medline

Raz N, Gunning FM, Head D, Dupuis JH, McQuain J, Briggs SD, Loken WJ, Thornton AE, Acker JD (1997) Selective aging of the human cerebral cortex observed in vivo: differential vulnerability of the prefrontal gray matter. Cereb Cortex 7:268-282. CrossRef Medline

Resnick SM, Pham DL, Kraut MA, Zonderman AB, Davatzikos C (2003) Longitudinal magnetic resonance imaging studies of older adults: a shrinking brain. J Neurosci 23:3295-3301. Medline

Reuter-Lorenz PA, Cappell KA (2008) Neurocognitive aging and the compensation hypothesis. Curr Dir Psychol Sci 17:177-182. CrossRef

Reuter-Lorenz PA, Lustig C (2005) Brain aging: reorganizing discoveries about the aging mind. Curr Opin Neurobiol 15:245-251. CrossRef Medline

Reuter-Lorenz PA, Jonides J, Smith EE, Hartley A, Miller A, Marshuetz C,
Koeppe RA (2000) Age differences in the frontal lateralization of verbal and spatial working memory revealed by PET. J Cogn Neurosci 12:174187. CrossRef Medline

Rodd JM, Davis MH, Johnsrude IS (2005) The neural mechanisms of speech comprehension: fMRI studies of semantic ambiguity. Cereb Cortex 15: 1261-1269. Medline

Sadaghiani S, Scheeringa R, Lehongre K, Morillon B, Giraud AL, Kleinschmidt A (2010) Intrinsic connectivity networks, alpha oscillations, and tonic alertness: a simultaneous electroencephalography/functional magnetic resonance imaging study. J Neurosci 30:10243-10250. CrossRef Medline

Sadaghiani S, Scheeringa R, Lehongre K, Morillon B, Giraud AL, D’Esposito M, Kleinschmidt A (2012) Alpha-band phase synchrony is related to activity in the fronto-parietal adaptive control network. J Neurosci 32 14305-14310. CrossRef Medline

Salat DH, Buckner RL, Snyder AZ, Greve DN, Desikan RS, Busa E, Morris JC, Dale AM, Fischl B (2004) Thinning of the cerebral cortex in aging. Cereb Cortex 14:721-730. CrossRef Medline

Sandmann P, Dillier N, Eichele T, Meyer M, Kegel A, Pascual-Marqui RD, Marcar VL, Jäncke L, Debener S (2012) Visual activation of auditory cortex reflects maladaptive plasticity in cochlear implant users. Brain 135: 555-568. CrossRef Medline

Schneider-Garces NJ, Gordon BA, Brumback-Peltz CR, Shin E, Lee Y, Sutton BP, Maclin EL, Gratton G, Fabiani M (2010) Span, CRUNCH, and beyond: working memory capacity and the aging brain. J Cogn Neurosci 22:655-669. CrossRef Medline

Sharp DJ, Scott SK, Mehta MA, Wise RJ (2006) The neural correlates of declining performance with age: evidence for age-related changes in cognitive control. Cereb Cortex 16:1739-1749. Medline

Shenhav A, Botvinick MM, Cohen JD (2013) The expected value of control: an integrative theory of anterior cingulate cortex function. Neuron 79: 217-240. CrossRef Medline

Simmonds AJ, Wise RJ, Collins C, Redjep O, Sharp DJ, Iverson P, Leech R (2014) Parallel systems in the control of speech. Hum Brain Mapp 35: 1930-1943. CrossRef Medline

Souza PE, Boike KT, Witherell K, Tremblay K (2007) Prediction of speech recognition from audibility in older listeners with hearing loss: effects of age, amplification, and background noise. J Am Acad Audiol 18:54-65. CrossRef Medline

Stern Y, Rakitin BC, Habeck C, Gazes Y, Steffener J, Kumar A, Reuben A (2012) Task difficulty modulates young-old differences in network expression. Brain Res 1435:130-145. CrossRef Medline

Teipel SJ, Meindl T, Wagner M, Stieltjes B, Reuter S, Hauenstein KH, Filippi M, Ernemann U, Reiser MF, Hampel H (2010) Longitudinal changes in fiber tract integrity in healthy aging and mild cognitive impairment: a DTI follow-up study. J Alzheimers Dis 22:507-522. Medline

Tombaugh TN, McIntyre NJ (1992) The Mini-Mental State Examination: a comprehensive review. J Am Geriatr Soc 40:922-935. Medline

Tourville JA, Guenther FH (2011) The DIVA model: a neural theory of speech acquisition and production. Lang Cogn Process 26:952-981. CrossRef Medline

Tun PA, O'Kane G, Wingfield A (2002) Distraction by competing speech in young and older adult listeners. Psychol Aging 17:453-467. CrossRef Medline

Tun PA, McCoy S, Wingfield A (2009) Aging, hearing acuity, and the attentional costs of effortful listening. Psychol Aging 24:761-766. CrossRef Medline

Uncapher MR, Rugg MD (2005) Effects of divided attention on fMRI correlates of memory encoding. J Cogn Neurosci 17:1923-1935. CrossRef Medline

Vaden KI Jr, Muftuler LT, Hickok G (2010) Phonological repetitionsuppression in bilateral superior temporal sulci. Neuroimage 49:10181023. CrossRef Medline

Vaden KI Jr, Gebregziabher M, Kuchinsky SE, Eckert MA (2012) Multiple imputation of missing fMRI data in whole brain analysis. Neuroimage 60:1843-1855. CrossRef Medline

Vaden KI Jr, Kuchinsky SE, Cute SL, Ahlstrom JB, Dubno JR, Eckert MA (2013) The cingulo-opercular network provides word-recognition benefit. J Neurosci 33:18979-18986. CrossRef Medline

Vetter P, Smith FW, Muckli L (2014) Decoding sound and imagery content in early visual cortex. Curr Biol 24:1256-1262. CrossRef Medline 
Wandell BA, Yeatman JD (2013) Biological development of reading circuits. Curr Opin Neurobiol 23:261-268. CrossRef Medline

Weissman DH, Roberts KC, Visscher KM, Woldorff MG (2006) The neural bases of momentary lapses in attention. Nat Neurosci 9:971-978. CrossRef Medline

Westin CF, Maier SE, Mamata H, Nabavi A, Jolesz FA, Kikinis R (2002) Processing and visualization for diffusion tensor MRI. Med Image Anal 6:93-108. CrossRef Medline

Wierenga CE, Benjamin M, Gopinath K, Perlstein WM, Leonard CM, Rothi LJ, Conway T, Cato MA, Briggs R, Crosson B (2008) Age-related changes in word retrieval: role of bilateral frontal and subcortical networks. Neurobiol Aging 29:436-451. CrossRef Medline

Wild CJ, Yusuf A, Wilson DE, Peelle JE, Davis MH, Johnsrude IS (2012) Effortful listening: the processing of degraded speech depends critically on attention. J Neurosci 32:14010-14021. CrossRef Medline

Wilke M (2012) An alternative approach towards assessing and accounting for individual motion in fMRI timeseries. Neuroimage 59:2062-2072. CrossRef Medline
Wilson RH, Trivette CP, Williams DA, Watts KL (2012) The effects of energetic and informational masking on the Words-in-Noise Test (WIN). J Am Acad Audiol 23:522-533. CrossRef Medline

Worsley KJ (2006) FMRISTAT: a general statistical analysis for fMRI data. Available from: http://www.math.mcgill.ca/keith/fmristat. Accessed July 9, 2013.

Xue G, Aron AR, Poldrack RA (2008) Common neural substrates for inhibition of spoken and manual responses. Cereb Cortex 18:1923-1932. CrossRef Medline

Yeatman JD, Dougherty RF, Rykhlevskaia E, Sherbondy AJ, Deutsch GK, Wandell BA, Ben-Shachar M (2011) Anatomical properties of the arcuate fasciculus predict phonological and reading skills in children. J Cogn Neurosci 23:3304-3317. CrossRef Medline

Yeatman JD, Dougherty RF, Myall NJ, Wandell BA, Feldman HM (2012) Tract profiles of white matter properties: automating fiber-tract quantification. PLoS One 7:e49790. CrossRef Medline

Yeatman JD, Wandell BA, Mezer AA (2014) Lifespan maturation and degeneration of human brain white matter. Nat Commun 5 . 